\title{
Hydrogen at the Rooftop: Compact CPV-Hydrogen system to Convert Sunlight to Hydrogen
}

\author{
Muhammad Burhan', Muhammad Wakil Shahzad', Ng Kim Choon¹ \\ ${ }^{1}$ Water Desalination and Reuse Center (WDRC), Biological and Environmental Science \& \\ Engineering (BESE), King Abdullah University of Science and Technology, Thuwal 23955- \\ 6900, Saudi Arabia \\ Email: muhammad.burhan@kaust.edu.sa; muhammad.shahzad@kaust.edu.sa; \\ kimchoon.ng@kaust.edu.sa
}

\begin{abstract}
Despite being highest potential energy source, solar intermittency and low power density make it difficult for solar energy to compete with the conventional power plants. Highly efficient concentrated photovoltaic (CPV) system provides best technology to be paired with the electrolytic hydrogen production, as a sustainable energy source with long term energy storage. However, the conventional gigantic design of CPV system limits its market and application to the open desert fields without any rooftop installation scope, unlike conventional PV. This makes CPV less popular among solar energy customers. This paper discusses the development of compact CPV-Hydrogen system for the rooftop application in the urban region. The in-house built compact CPV system works with hybrid solar tracking of $0.1^{\circ}$ accuracy, ensured through proposed double lens collimator based solar tracking sensor. With PEM based electrolyser, the compact CPV-hydrogen system showed $28 \%$ CPV efficiency and $18 \%$ sunlight to hydrogen (STH) efficiency, for rooftop operation in tropical region of Singapore. For plant designers, the solar to hydrogen production rating of $217 \mathrm{kWh}_{\mathrm{e}} / \mathrm{kg}_{\mathrm{H} 2}$ has been presented with $15 \%$ STH daily average efficiency, recorded from the long term field operation of the system.
\end{abstract}

Keywords: CPV, Hydrogen, Solar to Hydrogen, Concentrated Photovoltaic, Solar Cell.

\section{Introduction}

In current alarming situation of greenhouse gas emissions, global warming is drastically affecting the environment [1-4]. Use of renewable energy resources as primary energy supply is the only solution for sustainable future [5-8]. Among all of the energy sources, solar energy has the highest energy potential that is many times higher than the current global energy demand [9-11]. On the other hand, solar energy is only available during diurnal period, but with intermittent supply [12]. In order to compete with the conventional fossil fuel based power plants, the sustainable energy source must also be able to provide steady power supply with high energy density [13]. However, due to solar intermittency, there is a need for energy storage system for steady power supply [14].

The simplest method of solar energy utilization is its conversion into electricity through solar cell. Although, conventional single junction solar cells are having 99\% share in current photovoltaic market [15], but they do not offer the highest efficiency. The multi-junction solar 
cell (MJC) provides highest efficiency of 46\% [16] which is 2-3 times higher than the conventional single junction cells [17]. However, due to higher material cost, they are utilized as concentrated photovoltaic (CPV) system [18]; highly efficient photovoltaic technology of the time.

Despite highest efficiency, CPV technology is only having a minor share in the photovoltaic market [19]. Conventional gigantic design of CPV unit is the main reason of its limited application scope [20,21], which is only suitable and targeted for the open desert field operation as CPV can only respond to beam radiation of solar energy [22]. For that, it tracks sun movement during its operation. On the other hand, the conventional single junction flat plate PV system has significant share of its installations as rooftop system. Currently, most of the countries are planning to increase the rooftop installations of PV systems to $40-50 \%$ of their total capacity [23]. Contrariwise, CPV technology appeared to be unattractive with less customers due to its limited application scope as it is only available as gigantic units. Therefore, there is a need to have a compact system design which should not only eliminate the installation related restriction of CPV but it should also be easily available for the customers of each capacity level.

Although, CPV system can convert solar radiations into electricity, a high grade energy, with highest efficiency but it still remains intermittent due to unsteady availability of solar radiations [24]. Conventional electrochemical energy storage i.e. battery can only provide a feasible and economical solution when the need is for short term energy storage and for a small capacity system [25]. In order to be a primary energy source, there is a need to have long term energy storage capability of 10-20 years, with high power density [26]. Electrolytic hydrogen production from water splitting, not only provides a sustainable long term energy storage option but also an alternate sustainable fuel with high power density [27]. It can not only be converted back into electricity when needed, using fuel cell, but it can also be exported as a fuel where it is needed [28]. Therefore, with compact CPV system, such technology will not only be in the reach of every customer but by coupling it with electrolytic hydrogen system, a sustainable and highly efficient energy source will be available at the rooftop of every commercial or housing building. The main restriction for the compact CPV design is the development of cost effective and highly accurate solar tracking system. In addition, for compact CPV system, larger number of solar tracking units are needed and due to highly accurate solar tracking requirements, the overall cost of system increases for the same capacity. Therefore, this demands to develop a cost effect but highly accurate and compact tracking unit for compact CPV design. Moreover, all of the commercially available solar tracking sensors, with tracking accuracy as of CPV standard, cannot provide an economical solution due to their high capital cost $[\mathbf{2 9 , 3 0 ]}$ as more number of units are needed for the compact CPV system design.

In this paper, a prototype of compact CPV-hydrogen system is designed, developed and tested for rooftop application. A compact solar tracking system is developed with highly accurate, low cost, novel solar tracking sensor and microcontroller based control. On the other hand, as CPV systems are only considered to be suitable for open desert field regions with high DNI availability, therefore, the performance of developed CPV-hydrogen system is also tested for 
urban rooftop application in tropical environment. The system was installed at the rooftop of EA building at NUS Singapore. It showed maximum sunlight to hydrogen (STH) efficiency of $18 \%$ which is not only 4 times higher than the conventional PV-hydrogen system (i.e. PV efficiency of $7.5 \%$ [31] and electrolyser efficiency of 68\% [32]) but it is also two times higher than the electrical efficiency of PV system alone. The developed system showed daily average STH efficiency of $15 \%$ and STH production rating of $217 \mathrm{kWh} / \mathrm{kg}$. Such proposed system will not only introduce a highly efficient photovoltaic system for everyone but also a sustainable energy source with steady power supply.

\section{Compact CPV-Hydrogen System Design and Scope}

The conceptual representation of compact CPV-Hydrogen system is shown in Fig. 1. The overall system has two sub-components i.e. CPV system and hydrogen production/reutilization/storage system. In current study, the main focus is the development of compact CPV system that will not only eliminate its installation restrictions but it will also provide CPV the same application scope as that of conventional PV i.e. operation at the rooftop of residential or commercial buildings. However, by utilizing such compact CPV system, a highly efficient prototype of CPV-hydrogen system will be developed and tested for its operation under tropical weather conditions of Singapore. The excess electrical power produced by the CPV will be converted into hydrogen/oxygen by electrolytic splitting of water molecule. Such produced hydrogen can not only be converted back into electricity when needed, using fuel cell, but it can also be transported to other places as a fuel where it can be directly burnt or converted back into electricity. Such compact CPV-hydrogen system will not only boost the market share of highly efficient CPV system with steady power supply and broader application scope, but it will also provide a sustainable power source at the rooftop of each housing unit. Beside power production system, such solar energy system can also be used for sustainable hydrogen and oxygen production for process use in industries. However, oxygen can be used as an industrial disinfecting agent, after converting into ozone.

The CPV system can be further split up into two systems i.e. CPV module, consisting of optical assembly of lenses or reflectors with the multi-junction solar cell (MJC), and solar tracking unit. Current compact CPV system design focuses on the design of solar tracking units. Due to larger number of tracking units needed for compact CPV design, the tracking unit must be simple and cost effective. Fig. 2 shows the design schematic of compact CPV unit and proposed solar tracking sensor. As shown, the CPV unit consists of two axis solar tracker, onto which the CPV module is mounted. Solar tracking system can be further divided into its mechanical assembly and control circuit. The mechanical assembly provides support structure and mechanical drive, consisting of worm gear and wheel. On the other hand, the control circuit is based upon the motor drivers and the central microcontroller that controls and defines the solar tracker movement. The solar tracking system needed for CPV system is different than that of the conventional PV systems. CPV systems require tracking accuracy of order $0.1^{\circ}-0.3^{\circ}$ which is about 10-100 times higher than that of conventional PV tracking units. If such high tracking accuracy is not achieved then the CPV power output can drop from maximum to zero. In order to ensure high tracking accuracy, hybrid tracking algorithm is utilized for the proposed compact CPV unit. 
The hybrid tracking algorithm is based upon both passive (astronomical) and active (optical) tracking algorithms. The passive tracking algorithm utilizes predefined solar geometry model [33] to determine the sun position at any place and any time of the day. Azimuth and zenith are two tracking angles which define the sun position in horizontal and vertical planes, respectively. The azimuth angle ' $\theta_{\mathrm{a}}$ ' is referenced from south in horizontal plane. However, the zenith angle ' $\theta_{\mathrm{z}}$ ' is referenced from horizontal level, in vertical plane. Both zenith and azimuth angles are given by equations (1) and (2A) or (2B), respectively.

$$
\theta_{z}=\cos ^{-1}\{\sin \phi \sin \delta+\cos \phi \cos \delta \cos \omega\}
$$

If $\omega>0$,

$$
\theta_{a}=360-\left[90+\cos ^{-1} \frac{\sin \delta-\sin \left(90-\theta_{z}\right) \sin \phi}{\cos \left(90-\theta_{z}\right) \cos \phi}\right]
$$

If $\omega<0$,

$$
\theta_{a}=90+\cos ^{-1} \frac{\sin \delta-\sin \left(90-\theta_{z}\right) \sin \phi}{\cos \left(90-\theta_{z}\right) \cos \phi}
$$

where ' $\omega$ ', ' $\delta$ ' and ' $\varnothing$ ' are hour angle, declination angle and latitude, respectively. The passive or astronomical tracking algorithm works as per defined solar position. However, in such case the tracking accuracy cannot be ensured as astronomical tracking is based upon open loop configuration, with no feedback. The mechanical drive is prone to backlash which can easily introduce tracking error. Therefore, in order to ensure required tracking accuracy, there is a need for real time feedback from solar tracking sensor, regarding solar position.

Fig. 2 shows the design and arrangement of proposed double lens collimator based solar tracking sensor. The solar tracking sensor is based upon two parts. First one is the optical assembly that amplifies the solar radiations and directs the resultant beam to an array of photosensors, which provides the required feedback in form of electrical signal. The optical collimator is based upon a certain arrangement of convex and concave lenses, sharing same focal point. The parallel solar rays, after passing through collimator, are converted into a concentrated form of collimated beam. The convex lens converges the parallel rays at its focal point. However, the concave lens, placed in the path of these converging rays, makes them parallel again as both lenses share the same focal point. Such concentrated but collimated beam is then directed at the centre of photosensor array, appearing as a concentrated bright spot. During operation, the solar tracking sensor is aligned with the tracker position such that when tracker is accurately facing towards the sun, the concentrated bright spot is exactly in the centre of photosensors array. In case of tracking error, the solar radiations, received by the solar tracking sensor, do not remain parallel to its optical axis. As a result of this misalignment, the concentrated bright spot deviates from its centre position. When the tracking error exceeds from tracking limit, the deviation of bright spot increases to such an extent that it hits any of the phtosensor in the array. In this case, a feedback signal is generated by the corresponding 
photosensor, which is translated by the control circuit of solar tracker as a tracking error. According to the position of each of the photosensor in the array, the microcontroller is programmed in such a way that it moves trackers accordingly, so that the bright sport again comes in the centre of photosensors array. As far as the concentrated bright spot remains inside the photo-sensor array, the tracker is assumed to be accurately tracking the sun within the defined error limits. The distance ' $\mathrm{S}$ ' between convex and concave lenses, and the thickness of concentrated collimated beam ' $b_{t}$ ' can be calculated by equations (3) and (4), respectively.

$$
S=f_{c x}+\left(-f_{c n}\right)
$$

The ray tracing simulation of proposed solar tracking sensor is also shown at the right side of Fig. 2. It can be seen that a perfect collimated beam can be obtained after concave lens. It must be noted that the distance between concave lens and photosensor array defines the sensitivity of solar tracking sensor. In addition, the distance among the photosensors in the array defines the error limit of the solar tracking unit.

As mentioned before, the movement of the solar tracker is managed by the control box which generates the required tracking signals, according to the hybrid tracking algorithm. For compact CPV system design, such control box must simple, robust and cost effective so that it can be easily implemented with required accuracy of CPV system. A simple schematic of microcontroller based control box for compact CPV system, is shown in Fig. 3. The heart of the control box is the microcontroller that implements the hybrid tracking algorithm and controls the tracker movements accordingly. The GPS and real time clock (RTC) modules are used to get the required information of date, time, latitude and longitude of particular location, to implement the astronomical tracking algorithm. On the other hand, the solar tracking sensor is connected to microcontroller through ADC (analogue to digital converter) communication, to convert its analogue feedback signal into a digital signal so that it can be read and implemented by the microcontroller. Based upon the required tracking information, the tracker movement is controlled by sending signals to the motor drivers.

\section{Developed CPV-Hydrogen System and Testing Methodology}

According to the proposed design of compact CPV system, as demonstrated in the previous section, a working prototype of compact CPV-hydrogen system is developed at the rooftop of EA building in NUS Singapore. The developed prototype is shown in Fig. 4.

The developed CPV system is based upon a CPV module, utilizing 2x2 Fresnel lens array and triple junction InGaP/InGaAs/Ge solar cell. The CPV module is mounted onto the mechanical structure of compact two axis solar tracking unit. For the developed system, the gear ratio of 40 is implemented for azimuth driving assembly and gear ratio of 60 is implemented for zenith driving assembly. The high gear ratio for zenith axis is due to the high torque requirement as the weight 
of CPV module is supported by the zenith driving assembly. Therefore, by utilizing the stepper motor of resolution $1.8 \%$ step and stepper motor driver of ratio ' 16 ', the azimuth and zenith driving assemblies have resolution of $0.0028125^{\circ}$ and $0.001875^{\circ}$ per step, respectively as given by equation (5).

$$
\text { Tracker Movement } / \text { Step }=\frac{\text { Motor Step }}{\text { Driver Step } \times \text { Gear Ratio }}
$$

The developed control box for such a tracking system is also shown in Fig. 4. The hybrid tracking algorithm is developed in C-programming and compiled through codevisionAVR. A prototype of solar tracking sensor is also developed and connected to the microcontroller through ADC communication. The developed tracker is designed to have error sensing capability of as low as $0.1^{\circ}$. In hybrid tracking algorithm, the astronomical tracking acts as the main tracking method. However, when such passive tracking algorithm completes then the feedback from solar tracking sensor is obtained. If the feedback signal is low then this indicates that the tracker is accurately facing towards the sun. However, in case of high feedback signal, the tracker is adjusted such that the feedback signal drops to zero again. After ensuring the tracking accuracy through feedback signal, the hybrid tracking algorithm starts again and remains continued during the operation.

During CPV operation, the solar tracking system ensures that the Fresnel lens along with the whole CPV module, is facing towards the sun, within their acceptable optical error limit. The beam solar radiations, after passing through Fresnel lens, are converged at the inlet aperture of glass homogeniser which further directs and unformly distributes them over the MJC area. The multijunction cell, placed at the outlet aperture of glass homogeniser, converts the received solar radiations into electrical power. However, some of the energy is lost as heat which is dissipated through heat spreader and heat sink, place at the back side of MJC. The power output of CPV system is then supplied to the PEM electrolyser based hydrogen production unit, through MPPT (maximum power point tacking) device or DC-DC converter. PEM electrolyser has its own current-voltage (I-V) characteristics, which depend upon the amount of current flowing through the circuit. On the other hand, the solar cell has a certain operating point with maximum efficiency, at certain concentration. Therefore, for overall maximum system efficiency, it is very important for both of the units that they must operate at their optimum points.

The hydrogen production system is based upon a small stack of PEM electrolysers, where produced CPV electricity is used to split water into hydrogen and oxygen. The produced hydrogen/oxygen gases are then stored into cylinders for storage and further used. For this purpose, a mechanical compression system is developed, which not only compresses the produced gases into the storage cylinders but also helps to have the flow of gases through the production unit. The flow schematic of developed compact CPV-hydrogen system is shown in Fig. 5. All of the feedback signals from the system, either system production or sensor output, are recorded through central data logging unit, to analyse the system performance. In order to measure the quantity of produced gases, they are first stored temporarily over the water and by the amount of water displaced, as measured through level sensor of $\pm 1.5 \%$ accuracy, the quantity of produced gases is determined. Moreover, for testing and prototyping purpose, only single compressor is used for the storage of both types of gases, due to limited budget. However, in such case, proper 
flushing of line is required before switching the compressor to other gas supply mode, to avoid mixing of gases in the system.

The performance of the developed system is measured in terms of its power output and energy efficiency. The performance parameters which are measured for the system performance analysis, are given by equations (6) to (10).

$$
P_{C P V}=V_{C P V} \times I_{C P V}
$$

$$
\eta_{C P V}=\frac{P_{C P V}}{D N I \times A_{c o n}}
$$

$$
\eta_{E L}=\frac{\dot{n}_{E, H 2} \bullet 237200}{I_{E} \bullet U_{E}}=\frac{\eta_{E F} \bullet 1.23}{U_{E}}
$$

Where ' $\mathrm{V}_{\mathrm{CPV}}$ ' and ' $\mathrm{I}_{\mathrm{CPV}}$ ' are voltage and current output of CPV system, respectively and their product gives the total CPV power output ' $\mathrm{P}_{\mathrm{CPV}}$ ', as given by equation (6). The efficiency of CPV ' $\eta_{\mathrm{CPV}}$ ' is given by the ratio of input to output power i.e. equation (7). Here, DNI (Direct Normal Irradiance) represents the amount of solar beam radiations received by the CPV system, measured in $\mathrm{W} / \mathrm{m}^{2}$ using Eppleylab Pyrheliometer with $\pm 1 \%$ calibrated accuracy, and ' $\mathrm{A}_{\text {con }}$ ' gives the receiver area of Fresnel lens array. For electrolyser, the amount of hydrogen produced ' $\mathrm{n}_{\mathrm{E}, \mathrm{H} 2}$ ' is given by the equation (8) where ' $n_{E}$ ' represents the number of electrons needed for the electrolysis, 'F' represents the Farady constant, ' $\mathrm{N}_{\mathrm{EC}}$ ' represents the number of electrolyser cells connected in series, ' $\eta_{E F}$ ' represents the Farady efficiency and 'IE' represent the current flowing through the electrolyser. The efficiency of electrolyser ' $\eta_{\mathrm{EL}}$ ' is solely depending upon its operating voltage ' $\mathrm{UE}_{\mathrm{E}}$ ', as given by (9). The numerator of equation (9) gives the energy output in form of hydrogen as $237200 \mathrm{~J} / \mathrm{mol}$ represent the Gibs free energy of water electrolysis reaction, which is equivalent to $1.23 \mathrm{~V}$, called as thermos-neutral voltage. The overall STH efficiency of CPV-hydrogen system ' $\eta_{\mathrm{CPV} \_\mathrm{H} 2}$ ' is then given by the equation (10), which is the product of efficiencies of both units i.e. CPV and Electrolyser.

However, the efficiency of conventional PV system is based upon the global horizontal irradiance (GHI). Therefore, in case of PV, the STH can be calculated as.

$$
\eta_{P V}=\frac{P_{P V}}{G H I \times A_{c o n}}=\frac{V_{P V} \times I_{P V}}{G H I \times A_{c o n}}
$$

$$
\eta_{P V_{-} H 2}=\eta_{P V} \bullet \eta_{E L}
$$




\section{Results and discussion}

265

Before analysing the overall performance of developed compact CPV-hydrogen system, the individual performance of CPV and electrolyser units is evaluated. Fig. 6 shows the maximum performance of developed CPV system, in form of conversion efficiency with heat sink temperature and received DNI, during different times of the day. It can be seen that the CPV system showed maximum solar energy conversion efficiency of $28 \%$. However, the CPV efficiency slightly dropped to $25-26 \%$ in the noon time despite increase in the received DNI. Such drop in the efficiency is due to increase in the cell temperature which can be seen through increase in the heat sink temperature. With increase in the DNI, concentration at the cell area increases, resulting in more heat loss and consequently, the system efficiency drops slightly.

Fig. 7 shows the performance characteristics of PEM electrolyser used in the development of current system. Each data point is based upon the average value of five experimental data sets repeated under similar conditions. In addition, the measured experimental data set has uncertainty of $\pm 0.42 \%$ and confidence level of $98 \%$ for current, uncertainty of $\pm 0.43 \%$ and confidence level of $98 \%$ for voltage and uncertainty of $\pm 0.97 \%$ and confidence level of $95 \%$ for gas flow measurement. Therefore, Faraday efficiency has uncertainty of $\pm 1.39 \%$. From the I-V characteristics of the electrolyser, it can be seen that the electrolytic reaction is starting after $1.4 \mathrm{~V}$ and then a proportional trend can be seen between current and voltage of electrolyser. On the other hand, if we look at the Faraday efficiency of PEM electrolyser unit, it is almost 100\% throughout the range of operating voltage. Thus, equation (8) can also be used to calculate the instantaneous production of hydrogen, other than the gas quantity measurement system developed for this setup. Similar to the I-V characteristics of the electrolyser, its hydrogen production is also proportional to the operating voltage. However, higher operating voltage can reduce the system efficiency, as given by equation (9), because Farady efficiency is almost $100 \%$ for the complete range of operating voltage. Therefore, for larger gas production with high system efficiency, the slope of hydrogen production versus voltage graph must be higher instead of operating the system at higher voltage.

In order to analyse the performance variation of CPV-hydrogen system under real field condition, the system was operated for the whole day operation and the system performance curves are shown in Fig. 8. It must be noted that the DNI data was measured with uncertainty of $\pm 1 \%$ and confidence level of $96 \%$. On the other hand, CPV voltage and current measurements have uncertainties of $\pm 0.46 \%$ and $\pm 0.49 \%$, respectively with $97 \%$ confidence level. Therefore, the uncertainties in the CPV efficiency, electrolyser efficiency and STH efficiency are $\pm 1.67 \%$, $\pm 1.82 \%$ and $\pm 3.49 \%$, respectively. It can be seen that a maximum sunlight to hydrogen (STH) efficiency of $18 \%$ is recorded for the developed CPV-hydrogen system, which is about 2 times higher than the electrical efficiency of conventional PV modules. In the morning, with the increase in the DNI, the STH efficiency is increasing. However, after certain limit, further increase in DNI is cause drop in the STH efficiency. This trend can be explained with the maximum efficiency curve for CPV system. The CPV efficiency was increasing in the morning with increase in the DNI, due to increase in the concentration at the cell area. However, with further increase in the DNI, the efficiency slightly drops due to increase in the cell temperature at higher concentration, as explained above in Fig. 6. The CPV efficiency stabilizes at $24-25 \%$ while STH efficiency 
remains steady at $15 \%$. However, if electrolyser efficiency curve is observed, a continuous drop can be seen during first half of the day when DNI is increasing and a continuous increase occurs during other half of the day when DNI start to drop in the afternoon. With increase in the DNI, the power output of CPV also increases as there is a slight drop in the efficiency and consequently, the electrical power delivered to the electrolyser also increases, causing increase in the voltage and current of the electrolyser, as shown in Fig. 8. With continuous increase in the operating voltage of electrolyser, its efficiency drops continuously, as the efficiency only depends upon the operating voltage. However, when DNI starts to drop in the afternoon, the CPV power and electrolyser voltage drop as well, causing an increase in the efficiency of electrolyser.

From the system performance curves, it can be seen that a lot of parameters are simultaneously affecting the system performance. Thus, the true system performance cannot be rated by maximum power output or efficiency only because the real field conditions change throughout the day. For operation of the system like CPV, especially in the urban region with tropical weather where the system can only respond to beam part of solar radiations, the feasibility of such a system can only be justified with average real field performance instead of instantaneous maximum efficiency. Therefore, to analyse the feasibility of CPV-hydrogen system in tropical weather conditions, the system output was monitored for many days, under different weather conditions. Fig. 9 shows the daily average STH efficiency for different days with different amount of received beam radiations. It can be seen that with the increase in the amount of beam radiation received per day, the daily average STH efficiency is decreasing. The main cause for this drop is similar to the one given for Fig. 6 and Fig. 8 where efficiency of the system is decreasing with the increase in the DNI. The first reason is due to increase in the cell temperature with increase in DNI or concentration. However, the second reason is the drop in the electrolyser efficiency due to increase in its operating voltage which increases with increase in the power output. Such trend can be explained through Fig. 10 which shows the variation of hydrogen production rating with increase in the amount of received radiations. The hydrogen production rating is increasing with increase in the solar energy input i.e. for clear days. This increase in hydrogen production rating, on the other hand, depicts the lower electrolyser efficiency, as explained in Fig. 11. It can be seen that for higher rating or power consumption, the electrolyser efficiency is decreasing. These results of decreasing efficiency suggest to operate electrolyser cell at lower power or voltage. For larger production, multiple electrolyser cells can be connected in series for better system efficiency. The above charts does not encourage the operation of CPV-hydrogen systems in region with low DNI availability. In fact, these results show the feasible operation of CPV-hydrogen system even in the tropical region.

From this series of experiments, it can be seen that the system showed an average long term STH efficiency of $15 \%$. This efficiency is 1.5-2 times higher than the instantaneous electrical efficiency of conventional PV. In addition, the electrolyser showed average efficiency in the range of 66$70 \%$ with hydrogen production rating of $47-50 \mathrm{kWh} / \mathrm{kg}$. The CPV-hydrogen system showed an average production rating of $217 \mathrm{kWh} / \mathrm{kg}$.

From the plant designer's point of view, the presented average performance data is very important to estimate the actual size of the system for the production requirement. It has been shown that the maximum rated performance does not reflect the actual field potential as the system output is 
continuously changing during field operation. The field conditions vary throughout the day and so as the system output. Therefore, the average long term performance gives the correct estimation of system output for the real field operation. Based upon the solar beam radiations availability, one can easily estimate the average hydrogen production rating and so as the electrolyser efficiency. This can give the average STH efficiency which can be used to calculate the system size or area, for the certain hydrogen production requirement. In addition, these full day experiments also validates the accuracy and performance of the developed compact two axis solar tracking system. This also shows the excellent performance and accuracy of the developed solar tracking sensor.

\section{Conclusion}

A compact CPV-hydrogen system has been successfully designed and developed for the rooftop application. The microcontroller based hybrid two axis solar tracking system has been developed for economical but highly accurate operation of the compact CPV field. A novel design of the solar tracking sensor has also been proposed for the cost effective operation, with high accuracy. The double collimator based solar tracking sensor showed tracking error sensitivity of as high as $0.1^{\circ}$, same as the accuracy of the commercially available solar tracking sensors for CPV application, but at a fraction of the cost. The main reason for such high accuracy at low cost is due to the development of optical based design of solar tracking sensor with ordinary photosensors, instead of utilizing highly sensitive photosensor based design with high cost. The developed CPV system showed stable operation at the rooftop, with required tracking accuracy throughout the days during long term operation. Moreover, the performance and production of developed CPVhydrogen system is also tested and evaluated for tropical weather conditions. A maximum of $18 \%$ STH efficiency was recorded for the CPV based hydrogen production system. Daily average efficiency of $15 \%$ was recorded with STH production rating of $217 \mathrm{kWh} / \mathrm{kg}$. This shows that despite only being responsive to the beam radiations, CPV system is still feasible for the operation in tropical region, with superior performance than the conventional PV.

Such proposed compact CPV system design will offer the same application scope to the CPV technology, as that of conventional PV system but with higher efficiency. In addition, a highly efficient sustainable hydrogen production system will be in the reach of every common customer that will help for the better utilization of solar energy with high power density, at any time, throughout the day.

\section{Acknowledgement}

This research was supported by the International Research Scholarship of Mechanical Engineering Department, National University of Singapore and collaborated with King Abdullah University of Science and Technology.

\section{Nomenclature}

$\begin{array}{llll}\text { STH } & \text { Sunlight to Hydrogen } & \text { PEM } & \text { Proton Exchange Membrane } \\ \mathrm{d} & \begin{array}{l}\text { Distance between photo-sensors } \\ (\mathrm{mm})\end{array} & \mathrm{h} & \begin{array}{l}\text { Distance between collimator and } \\ \text { photo-sensor array }(\mathrm{mm})\end{array}\end{array}$




\begin{tabular}{|c|c|c|c|}
\hline$\omega$ & Hour angle (degree) & $\delta$ & Declination angle (degree) \\
\hline$\theta_{\mathrm{a}}$ & Azimuth angle (degree) & $\theta_{\mathrm{z}}$ & Zenith angle (degree) \\
\hline DNI & Direct Normal Irradiance, $\left(\mathrm{W} / \mathrm{m}^{2}\right)$ & $\mathrm{A}_{\text {con }}$ & Area of Solar Concentrator $\left(\mathrm{m}^{2}\right)$ \\
\hline PSD & Position Sensitive Diode & $b_{t}$ & Collimated beam thickness (mm) \\
\hline $\mathrm{I}_{\mathrm{E}}$ & Electrolyser Current (A) & $\mathrm{S}$ & $\begin{array}{l}\text { Distance between collimating } \\
\text { lenses }(\mathrm{mm})\end{array}$ \\
\hline MJC & Multi-junction solar cell & $\mathrm{CPV}$ & Concentrated Photovoltaic \\
\hline PV & Photovoltaic & GHI & Global horizontal irradiance \\
\hline $\mathrm{f}_{\mathrm{cx}}$ & Focal length of convex lens (mm) & $\mathrm{f}_{\mathrm{cn}}$ & Focal length of concave lens (mm) \\
\hline $\mathrm{D}_{\mathrm{cx}}$ & Convex lens diameter $(\mathrm{mm})$ & $\varnothing$ & Latitude (degree) \\
\hline $\mathrm{ADC}$ & Analogue to Digital Converter & CTS & Colour Tracking Sensor \\
\hline RTC & Real Time Clock & GPS & Global positioning system \\
\hline $\mathrm{N}_{\mathrm{EC}}$ & Number of Cells of Electrolyser & $\mathrm{V}_{\mathrm{CPV}}$ & CPV Voltage (V) \\
\hline $\mathrm{I}_{\mathrm{E}}$ & Electrolyser Current (A) & $\eta_{\mathrm{EL}}$ & Electrolyser Efficiency (\%) \\
\hline$\dot{n}_{E, H 2}$ & $\begin{array}{l}\text { Hydrogen Production Flow Rate } \\
\text { from Electrolyser }(\mathrm{mol} / \mathrm{s})\end{array}$ & $\eta_{\mathrm{EF}}$ & $\begin{array}{l}\text { Faraday Efficiency of Electrolyser } \\
(\%)\end{array}$ \\
\hline$\eta_{\mathrm{CPV}}$ & CPV Efficiency (\%) & $\mathrm{P}_{\mathrm{CPV}}$ & CPV Power Output (W) \\
\hline $\mathrm{n}_{\mathrm{E}}$ & $\begin{array}{l}\text { Electrons Requirement for Water } \\
\text { Splitting }\end{array}$ & $\eta_{\mathrm{CPV} \_\mathrm{H} 2}$ & $\begin{array}{l}\text { Sunlight to Hydrogen (STH) } \\
\text { Efficiency for CPV (\%) }\end{array}$ \\
\hline$\eta_{\mathrm{PV}}$ & PV Efficiency (\%) & $\eta_{\mathrm{PV} \_\mathrm{H} 2}$ & $\begin{array}{l}\text { Sunlight to Hydrogen (STH) } \\
\text { Efficiency for PV (\%) }\end{array}$ \\
\hline $\mathrm{U}_{\mathrm{E}}$ & Electrolyser Cell Voltage (V) & $\mathrm{F}$ & Faraday Constant (A.s/mol) \\
\hline MPPT & Maximum Power Point Tracking & $\mathrm{I}_{\mathrm{CPV}}$ & CPV Current (A) \\
\hline
\end{tabular}

\section{References}

[1] Tehrani SS, Saffar-Avval M, Mansoori Z, Kalhori SB, Abbassi A, Dabir B, Sharif M. Development of a CHP/DH system for the new town of Parand: An opportunity to mitigate global warming in Middle East. Applied Thermal Engineering 2013, 59(1), 298-308.

[2] Bengtsson P, Eikevik T. Reducing the global warming impact of a household heat pump dishwasher using hydrocarbon refrigerants. Applied Thermal Engineering 2016, 99, 1295-302.

[3] Ozden E, Tari I. Energy-exergy and economic analyses of a hybrid solar-hydrogen renewable energy system in Ankara, Turkey. Applied Thermal Engineering 2016, 99, 169-78.

[4] Seifi H, Sadrameli SM. Improvement of renewable transportation fuel properties by deoxygenation process using thermal and catalytic cracking of triglycerides and their methyl esters. Applied Thermal Engineering 2016, 100, 1102-10.

[5] Li MJ, Zhao W, Chen X, Tao WQ. Economic analysis of a new class of vanadium redoxflow battery for medium-and large-scale energy storage in commercial applications with renewable energy. Applied Thermal Engineering 2017, 114, 802-14.

[6] Rasid MM, Murata J, Takano H. Fossil fuel cost saving maximization: Optimal allocation and sizing of Renewable-Energy Distributed Generation units considering uncertainty via Clonal Differential Evolution. Applied Thermal Engineering 2017, 114, 1424-32. 
[7] Ascione F, Bianco N, De Masi RF, De Stasio C, Mauro GM, Vanoli GP. Multi-objective optimization of the renewable energy mix for a building. Applied Thermal Engineering 2016, 101, 612-21.

[8] Burhan M, Oh SJ, Chua KJ, Ng KC. Solar to hydrogen: Compact and cost effective CPV field for rooftop operation and hydrogen production. Applied Energy 2017, 194, 255-66.

[9] Burhan M, Oh SJ, Chua KJE, Ng KC. Double lens collimator solar feedback sensor and master slave configuration: Development of compact and low cost two axis solar tracking system for CPV applications. Solar Energy 2016, 137, 352-363.

[10] Burhan M, Chua KJE, Ng KC. Long term hydrogen production potential of concentrated photovoltaic (CPV) system in tropical weather of Singapore. International Journal of Hydrogen Energy 2016, 41(38), 16729-16742.

[11] Burhan M, Chua $\mathrm{KJE}, \mathrm{Ng} \mathrm{KC}$. Electrical rating of concentrated photovoltaic (CPV) systems: long-term performance analysis and comparison to conventional PV systems. International Journal of Technology 2016, 7(2), 189-196. DOI: 10.14716/ijtech.v7i2.2983.

[12] Kong H, Hao Y, Wang H. A solar thermochemical fuel production system integrated with fossil fuel heat recuperation. Applied Thermal Engineering 2016, 108, 958-66.

[13] Burhan M, Shahzad MW, Ng KC. Development of performance model and optimization strategy for standalone operation of CPV-hydrogen system utilizing multi-junction solar cell. International Journal of Hydrogen Energy 2017, http://dx.doi.org/ 10.1016/j.ijhydene.2017.08.186

[14] Burhan M, Chua KJE, Ng KC. Sunlight to hydrogen conversion: Design optimization and energy management of concentrated photovoltaic (CPV-Hydrogen) system using micro genetic algorithm. Energy 2016, 99, 115-128.

[15] Muhammad B, Seung JO, Ng KC, Chun W. Experimental Investigation of Multijunction Solar Cell Using Two Axis Solar Tracker. In Applied Mechanics and Materials 2016 (Vol. 819, pp. 536-540). Trans Tech Publications.

[16] Burhan M., Chua KJE, Ng KC. Simulation and development of a multi-leg homogeniser concentrating assembly for concentrated photovoltaic (CPV) system with electrical rating analysis. Energy Conversion and Management 2016, 116, 58-71.

[17] Burhan M, Shahzad MW, Ng KC. Long-term performance potential of concentrated photovoltaic (CPV) systems. Energy Conversion and Management 2017, 148, 90-9.

[18] Mathur SS, Negi BS, Kandpal TC. Geometrical designs and performance analysis of a linear fresnel reflector solar concentrator with a flat horizontal absorber. International journal of energy research 1990, 14(1), 107-24. 
[19] Horne S, Conley G, Gordon J, Fork D, Meada P, Schrader E, Zimmermann T. A solid 500 sun compound concentrator PV design. In Photovoltaic Energy Conversion, Conference Record of the 2006 IEEE 4th World Conference 2006, 1, 694-697.

[20] Garboushian V, Stone KW, Slade A. 12 The Amonix High-Concentration Photovoltaic System. Concentrator Photovoltaics 2007, 130, 253.

[21] David FK, Stephen HJ. Laminated solar concentrating photovoltaic device. US Patent application publication; 2007. p. US2007/0256726.

[22] McConnell R. A Solar Concentrator Pathway to Low-Cost Electrolytic Hydrogen. Solar Hydrogen Generation 2008, 65-86.

[23] International Energy Agency (IEA). Trends 2015 in Photovoltaic Applications, Survey Report of Selected IEA Countries between 1992 and 2014. Report IEAPVPS T1-27; 2015.

\section{[24] BURHAN M. THEORETICAL AND EXPERIMENTAL STUDY OF} CONCENTRATED PHOTOVOLTAIC (CPV) SYSTEM WITH HYDROGEN PRODUCTION AS ENERGY STORAGE. (Doctoral dissertation); 2015.

[25] Agbossou K, Kolhe M, Hamelin J, Bose TK. Performance of a stand-alone renewable energy system based on energy storage as hydrogen. IEEE Transactions on energy Conversion 2004, 19(3), 633-40.

[26] Wang Z, Roberts RR, Naterer GF, Gabriel KS. Comparison of thermochemical, electrolytic, photoelectrolytic and photochemical solar-to-hydrogen production technologies. International journal of hydrogen energy 2012, 37(21), 16287-301.

[27] EVWorld. Energy content of fuels, <http://www.evworld.com/library/energy_numbers.pdf>, [Date retrieved: 20-12-2015].

[28] ForestBioEnergy. Sustainable forestry for bioenergy and biobased products. Energy basics. Fact Sheet 5.8, <http://www. forestbioenergy.net/trainingmaterials/fact-sheets/module5-fact-sheets/fact-sheet-5-8-energy-basics $>$. [Date retrieved: 20-12-2015].

[29] Abdallah K, Nijmeh S. Two axes sun tracking system with PLC control. Energy Conversion and Management 2004, 45(11-12), 1931-1939.

[30] Xu G, Zhong Z, Wang B, Guo R, Tian Y. Design of PSD based solar direction sensor. In Sixth International Symposium on Precision Mechanical Measurements 2013,89162K89162K. International Society for Optics and Photonics.

[31] Lin-Heng L, Lok-Ming C, Chia A, Gunawansa A, Harn-Wei K. Sustainability Matters, Challenges and Opportunities in Environmental Management in Asia. Pearson Education South Asia Pte Ltd, 2011. Singapore. 
468 [32] Khaselev O, Bansal A, Turner JA. High-efficiency integrated multijunction 469 photovoltaic/electrolysis systems for hydrogen production. International Journal of Hydrogen $470 \quad$ Energy 2001, 26(2), 127-132.

471 [33] Oh SJ, Burhan M, Ng KC, Kim Y, Chun W. Development and performance analysis of a 472 two-axis solar tracker for concentrated photovoltaics. International Journal of Energy 473 Research 2015, 39(7), 965-76. 
List of Figure Captions:

475 Figure 1: Schematic Scope of CPV-Hydrogen System

476 Figure 2: Design Schematic of Compact CPV System with Double Lens Collimator based Solar Tracking Sensor

478 Figure 3: Design Schematic of Control Box for Compact CPV System

479 Figure 4: Developed Prototype of Compact CPV-Hydrogen System for Rooftop Operation

480 Figure 5: Flow Schematic of Developed Compact CPV-Hydrogen System

481 Figure 6: Maximum Performance characteristics of Developed Compact CPV System

482 Figure 7: Performance Characteristics of PEM Electrolyser

483 Figure 8: Performance Curves for Compact CPV-Hydrogen System during Whole Day Operation

484 Figure 9: Variation of Daily Average STH efficiency against Daily Received Solar Energy for CPV-Hydrogen System

Figure 10: Variation of Daily Average Hydrogen Production Rating against Daily Received Solar Energy for CPV-Hydrogen System

Figure 11: Variation of Daily Average Hydrogen Production Rating against Daily Average Electrolyser Efficiency for CPV-Hydrogen System 


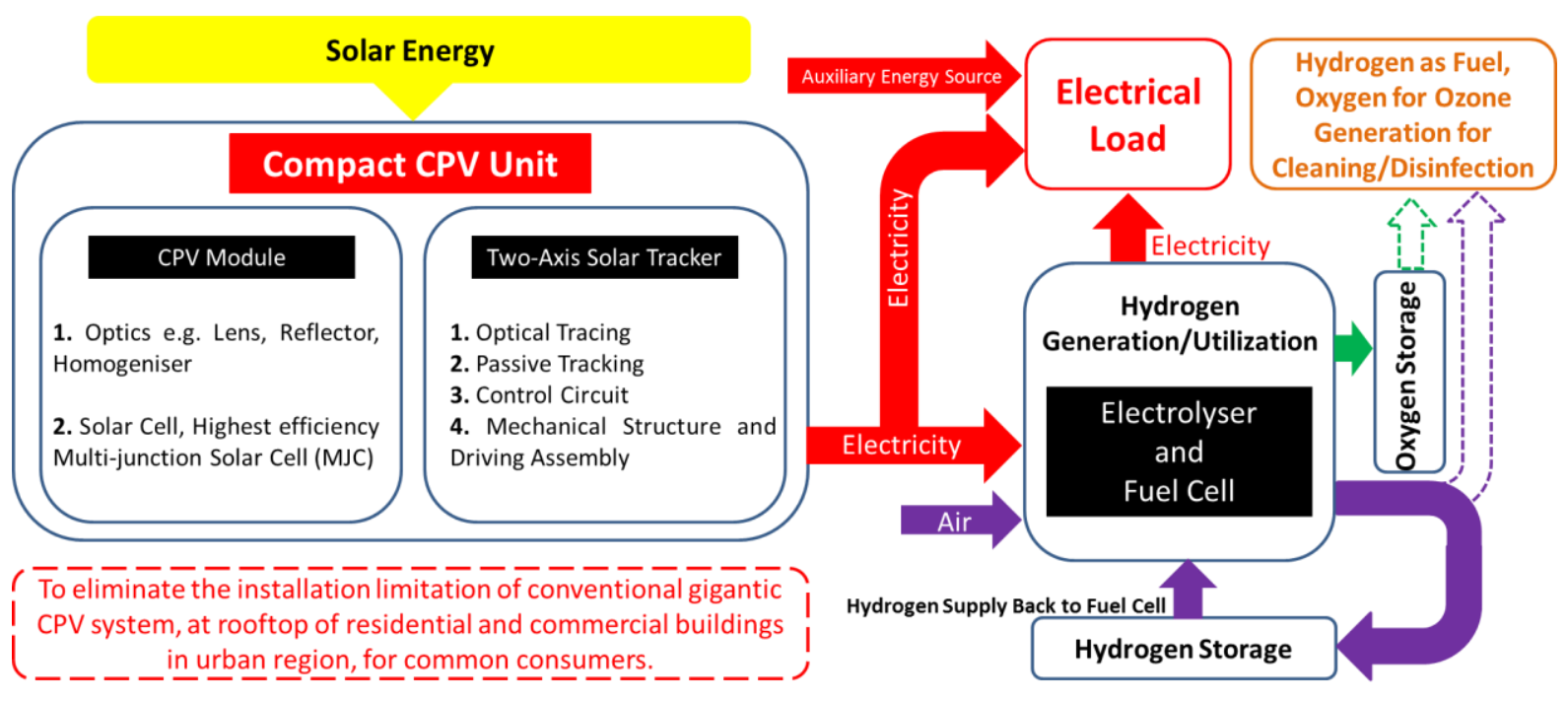

Figure 1: Schematic Scope of CPV-Hydrogen System 

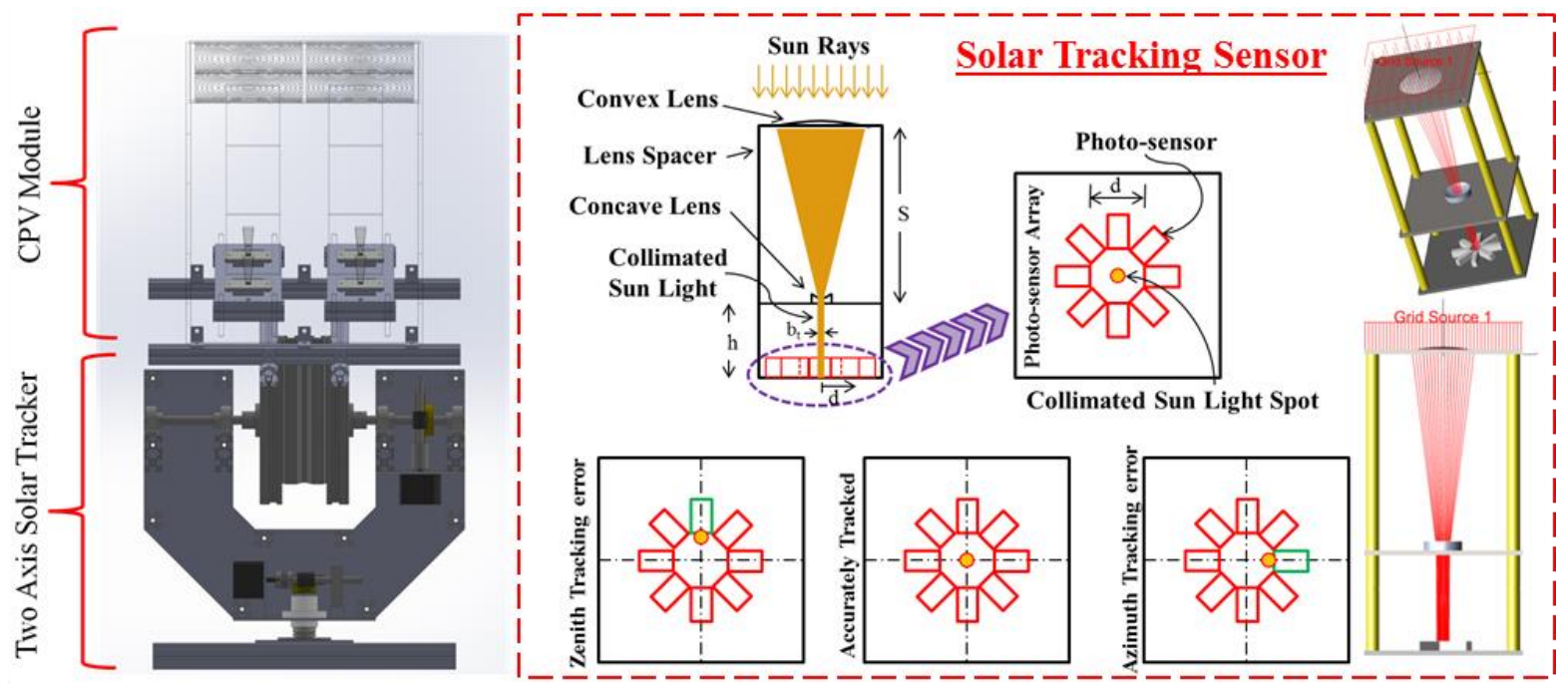

Figure 2: Design Schematic of Compact CPV System with Double Lens Collimator based

Solar Tracking Sensor 


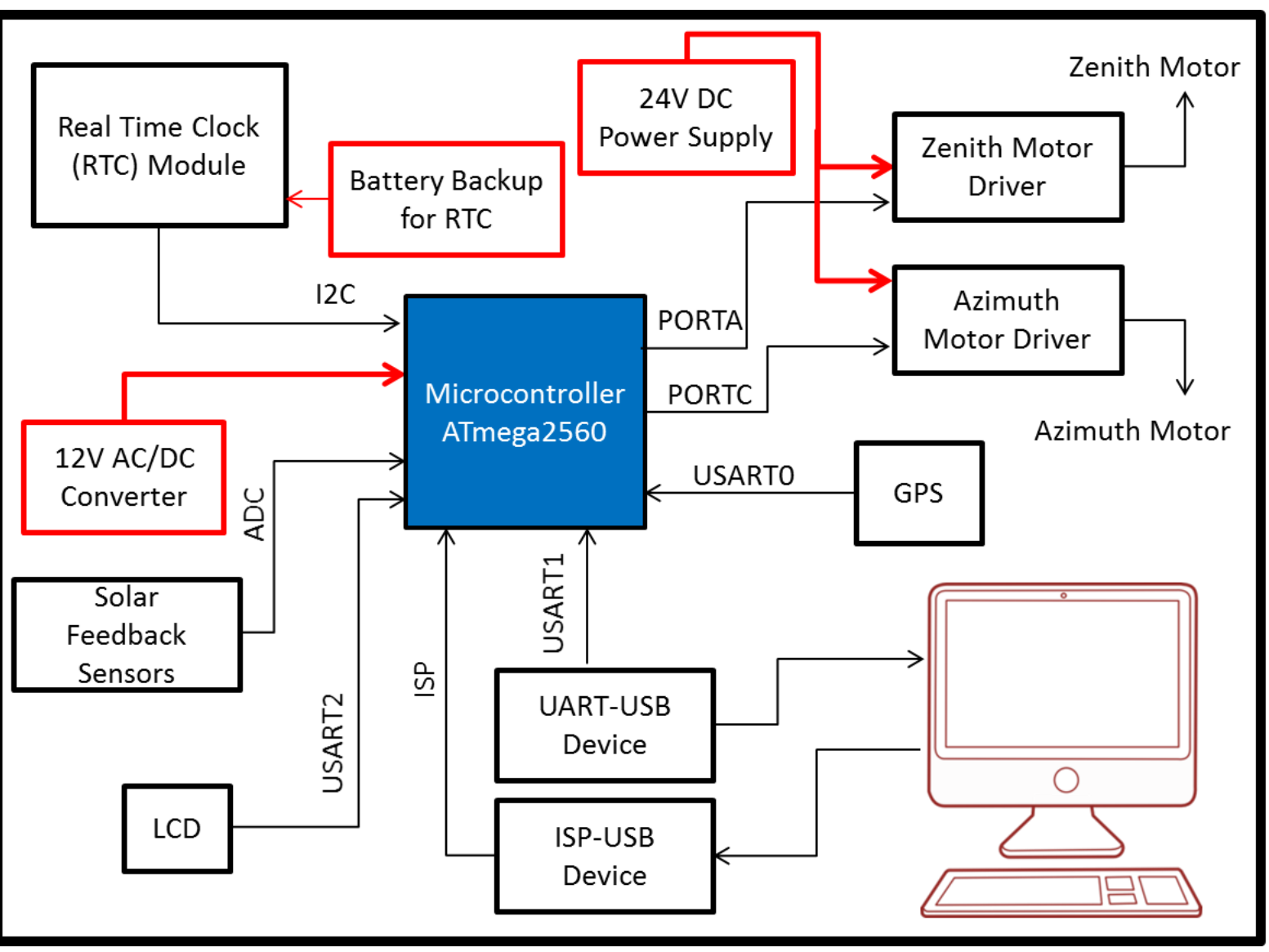

Figure 3: Design Schematic of Control Box for Compact CPV System 

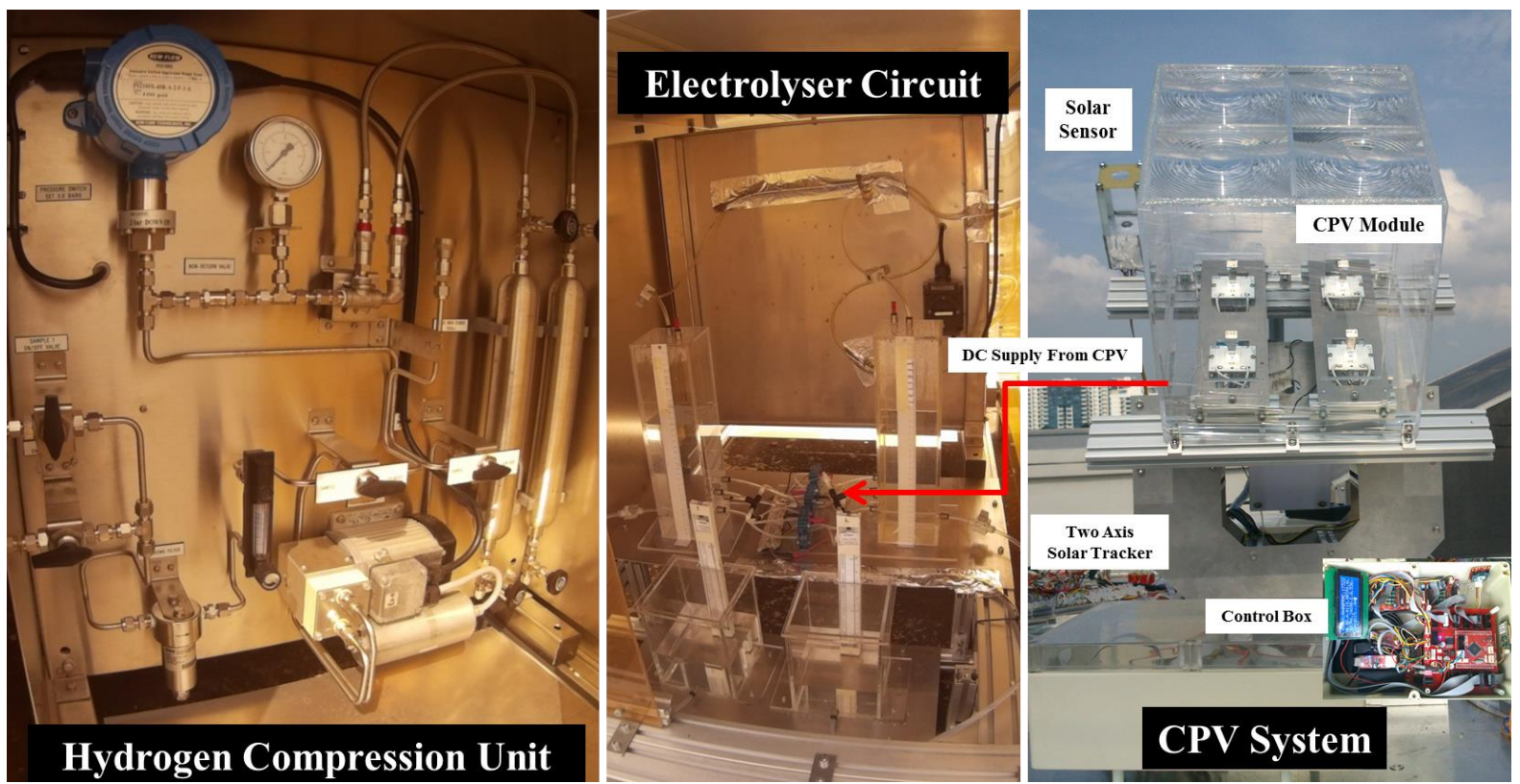

Figure 4: Developed Prototype of Compact CPV-Hydrogen System for Rooftop Operation 


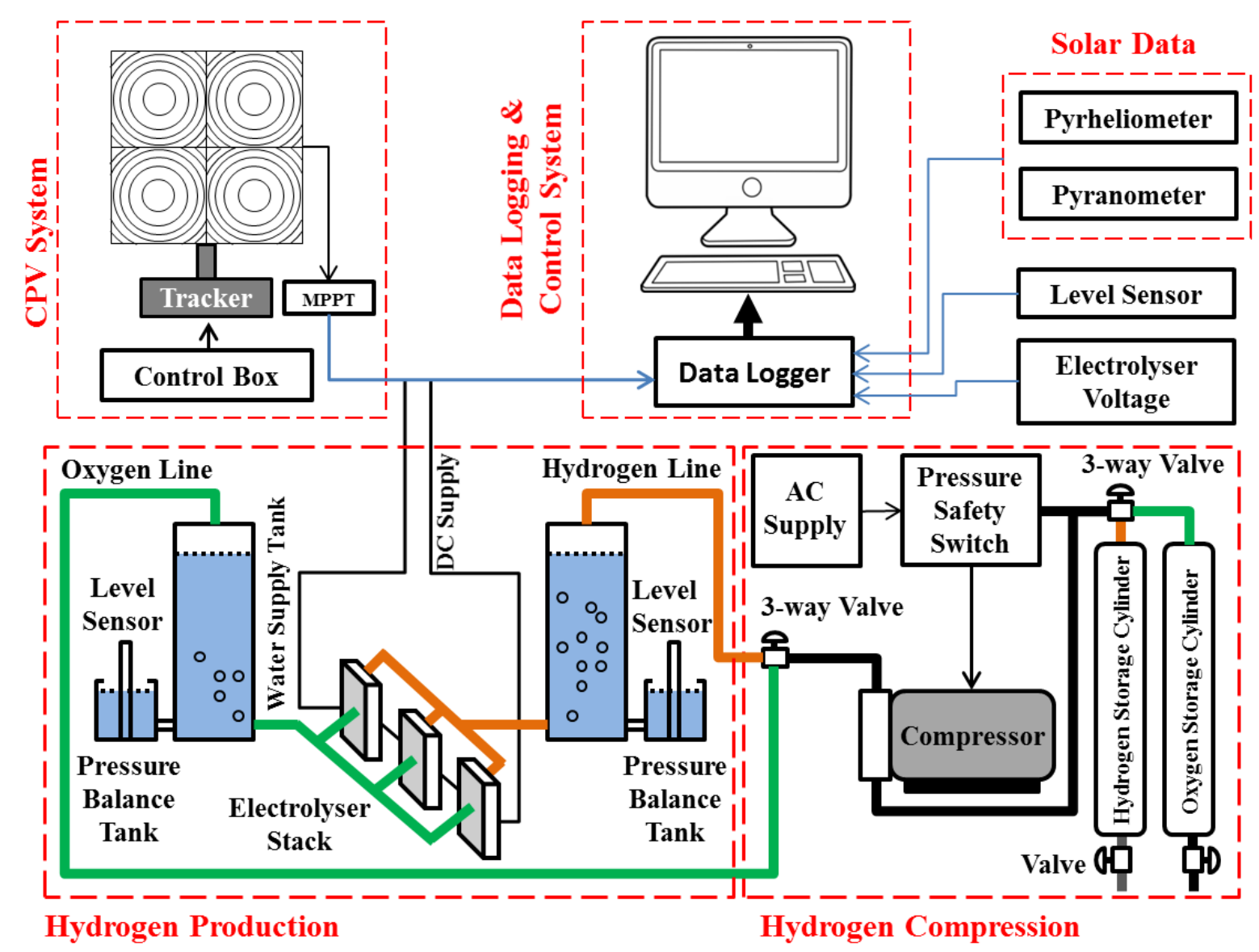

Figure 5: Flow Schematic of Developed Compact CPV-Hydrogen System 


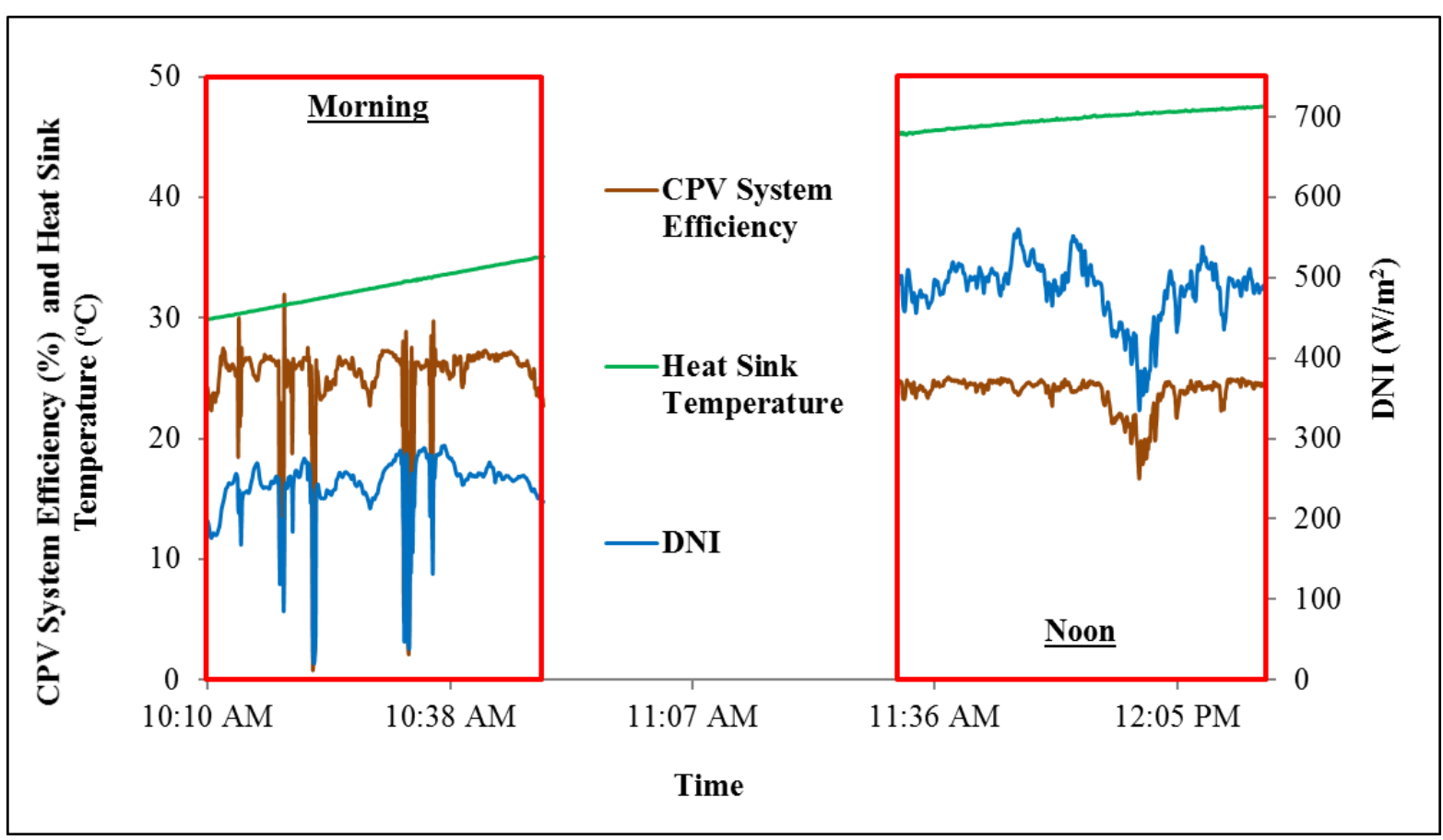

Figure 6: Maximum Performance characteristics of Developed Compact CPV System 
○H2 Flow Rate $(\mathrm{cm} 3 / \mathrm{sec}) \quad \Delta$ Electrolyser IV Curve $\quad \square$ Faraday Efficincy (\%)

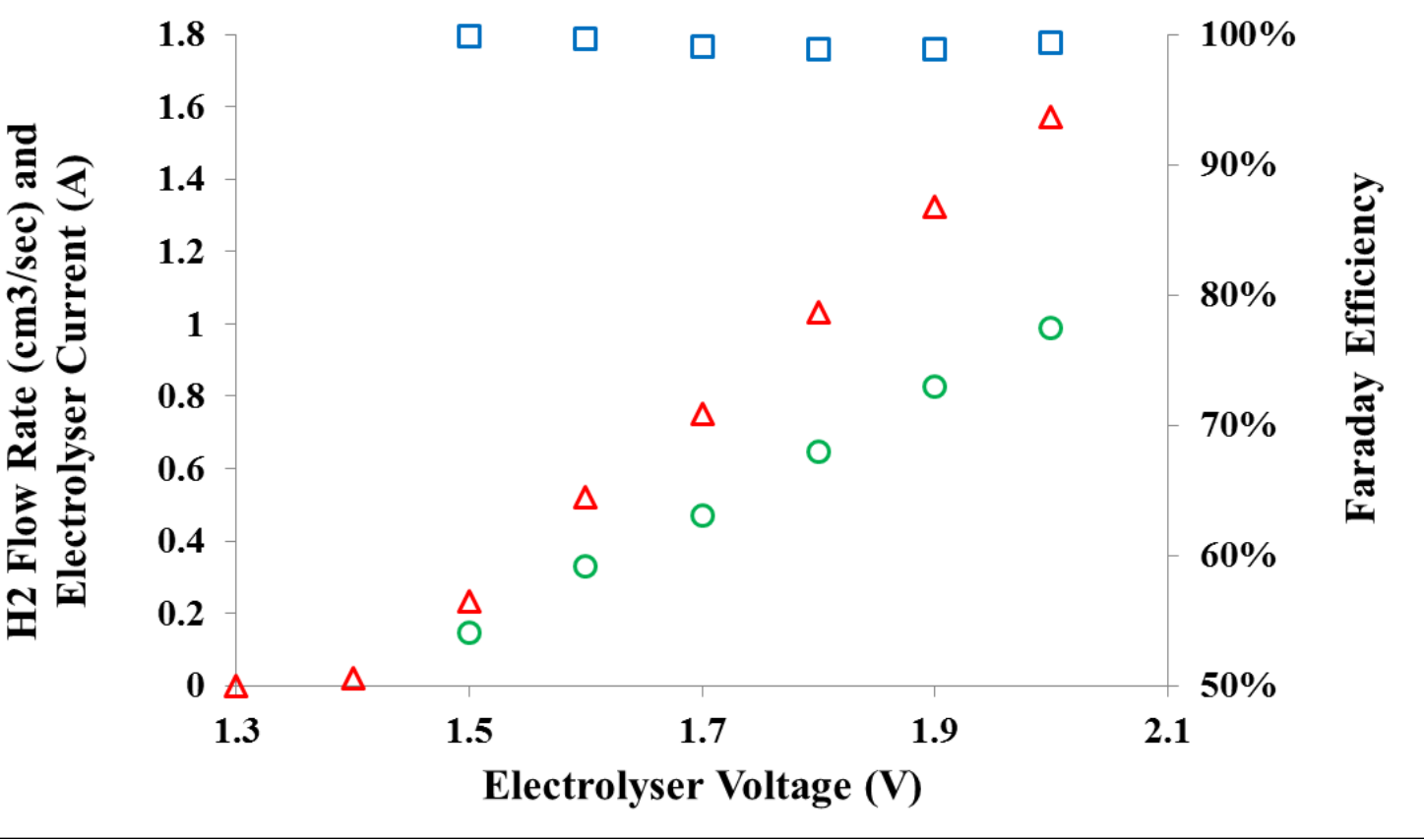




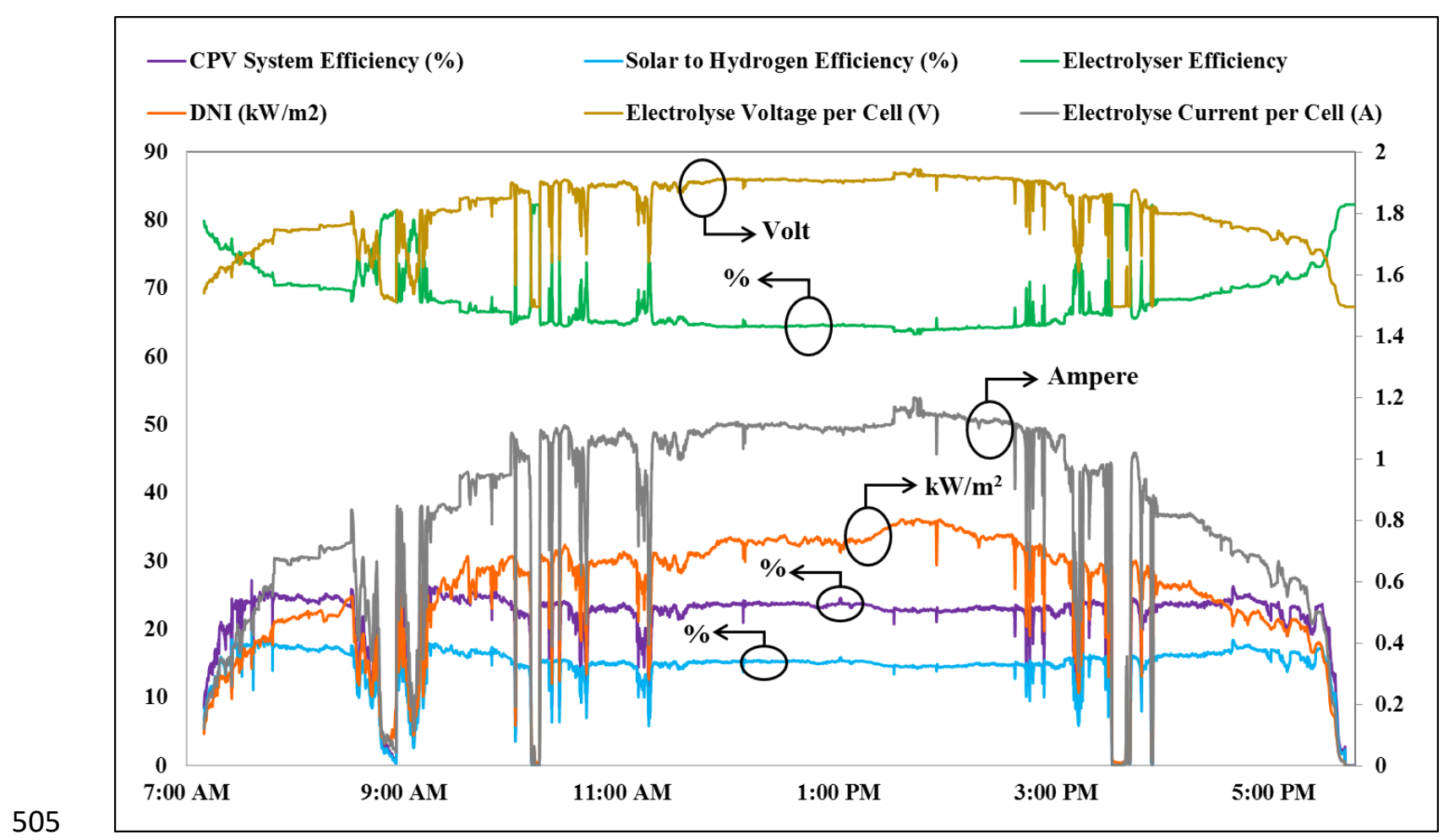

Figure 8: Performance Curves for Compact CPV-Hydrogen System during Whole Day 


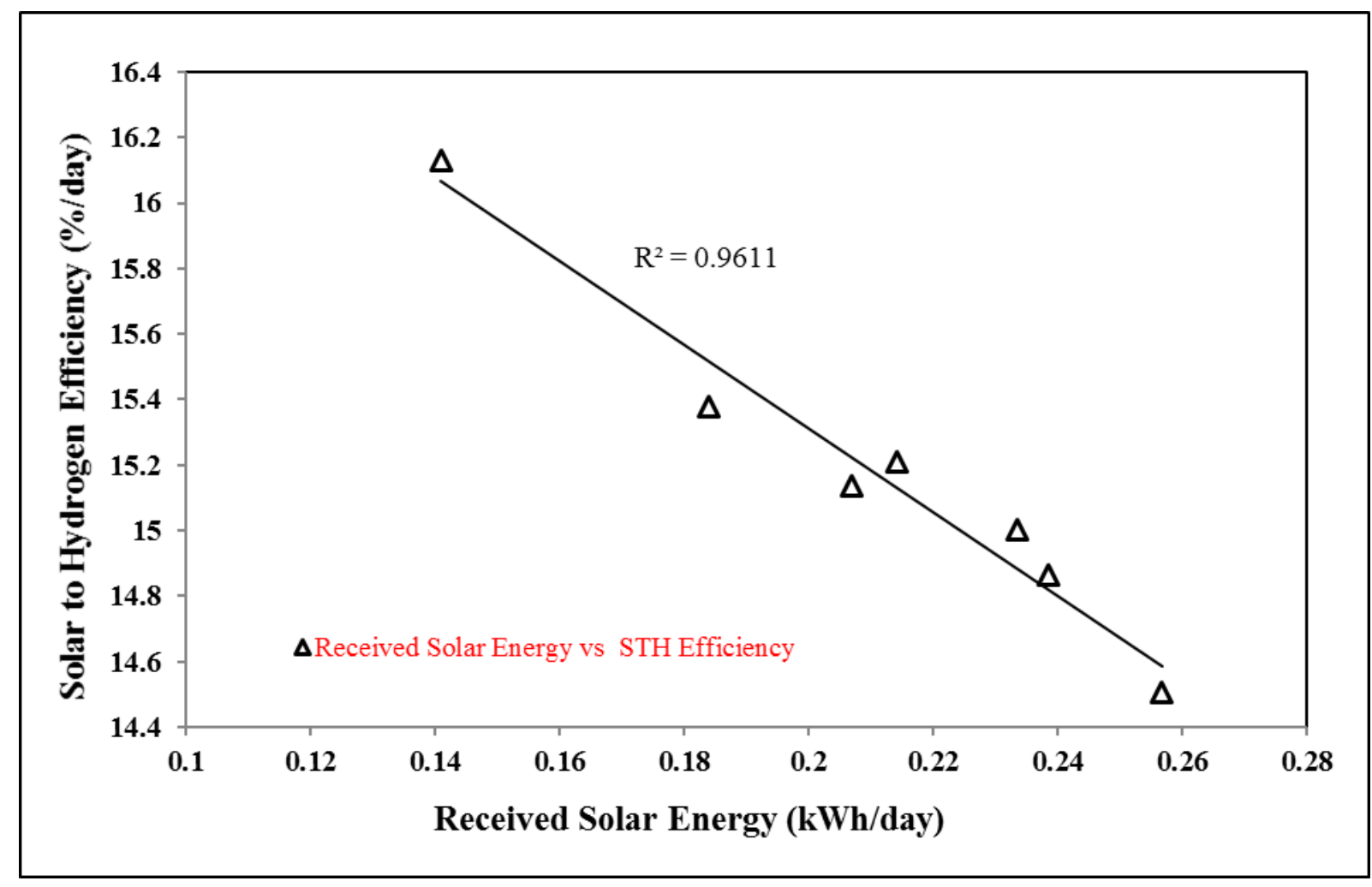

Figure 9: Variation of Daily Average STH efficiency against Daily Received Solar Energy for 


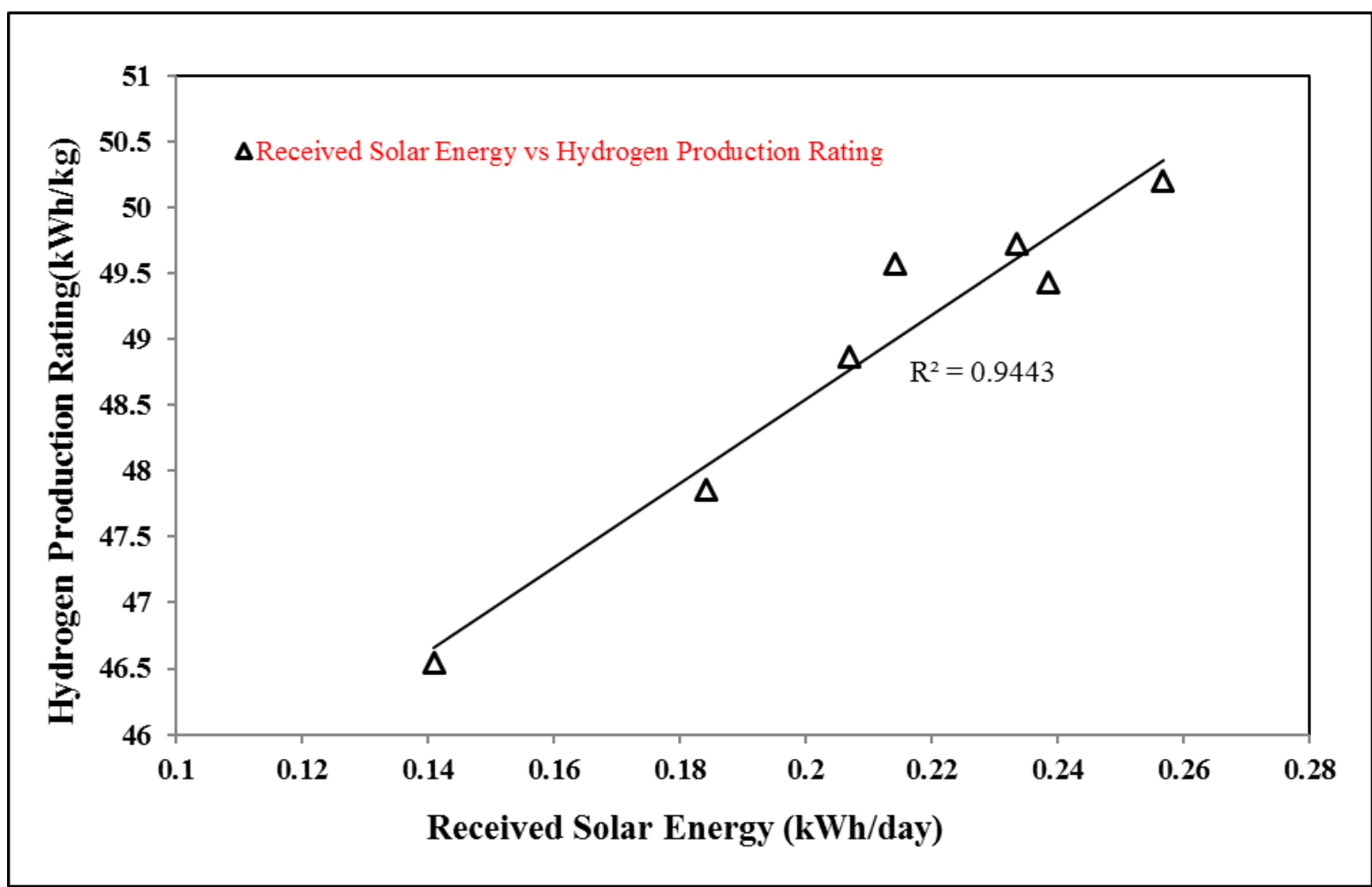

Figure 10: Variation of Daily Average Hydrogen Production Rating against Daily Received

Solar Energy for CPV-Hydrogen System 


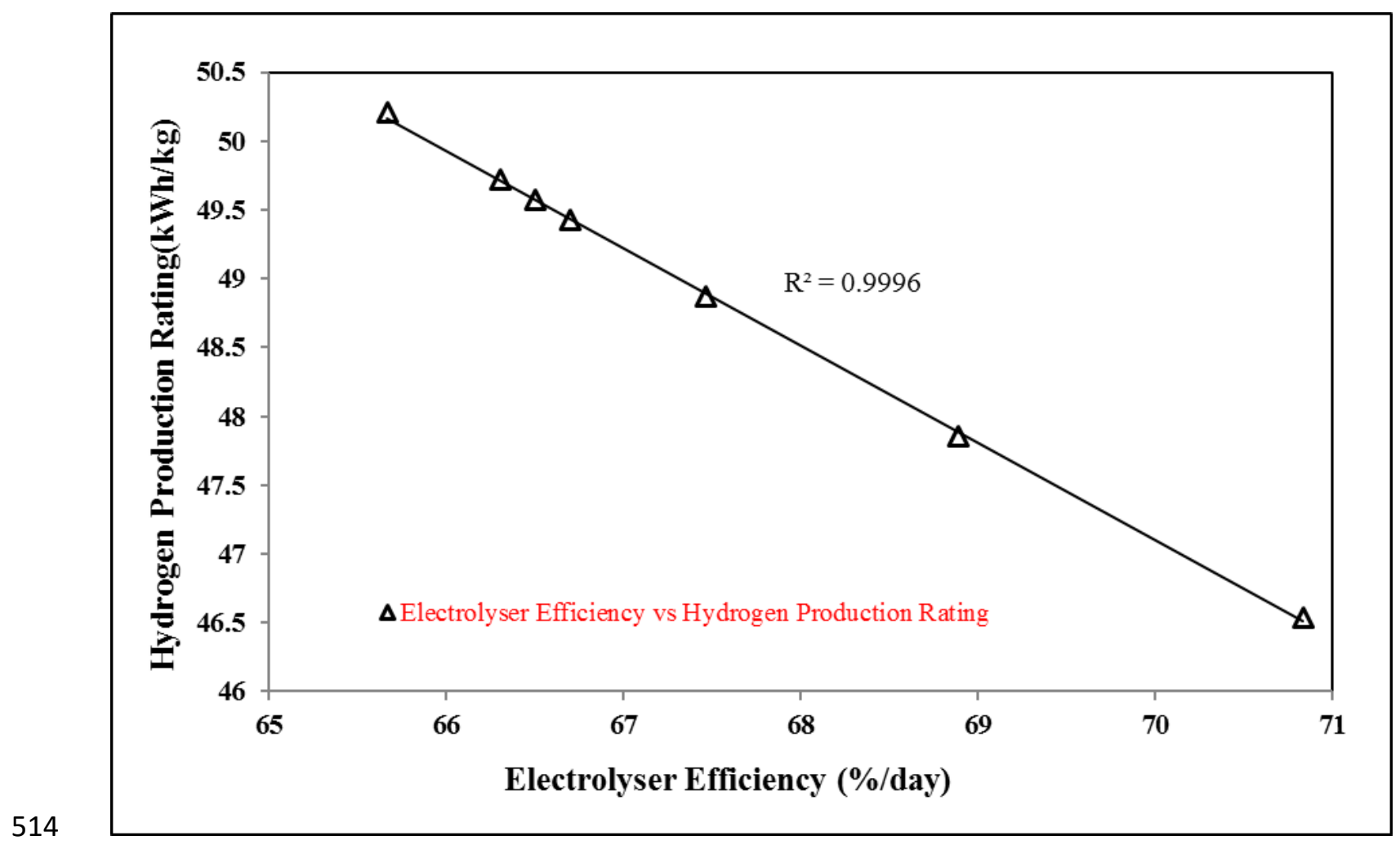

$515 \quad$ Figure 11: Variation of Daily Average Hydrogen Production Rating against Daily Average 